\title{
Accurate assessment of exposure using tracer gas measurements
}

Kierat, Wojciech; Bivolarova, Mariya ; Zavrl, Eva; Popiolek, Zbigniew ; Melikov, Arsen

Published in:

Building and Environment

Link to article, DOI:

10.1016/j.buildenv.2018.01.017

Publication date:

2018

Document Version

Peer reviewed version

Link back to DTU Orbit

Citation (APA):

Kierat, W., Bivolarova, M., Zavrl, E., Popiolek, Z., \& Melikov, A. (2018). Accurate assessment of exposure using tracer gas measurements. Building and Environment, 131, 163-173.

https://doi.org/10.1016/..buildenv.2018.01.017

\section{General rights}

Copyright and moral rights for the publications made accessible in the public portal are retained by the authors and/or other copyright owners and it is a condition of accessing publications that users recognise and abide by the legal requirements associated with these rights.

- Users may download and print one copy of any publication from the public portal for the purpose of private study or research.

- You may not further distribute the material or use it for any profit-making activity or commercial gain

- You may freely distribute the URL identifying the publication in the public portal

If you believe that this document breaches copyright please contact us providing details, and we will remove access to the work immediately and investigate your claim. 


\title{
Accurate assessment of exposure using tracer gas measurements
}

\author{
Wojciech Kierat $^{1 *}$, Mariya Bivolarova ${ }^{2}$, Eva Zavrl $^{2}$, Zbigniew Popiolek $^{1}$, Arsen Melikov $^{2}$ \\ ${ }^{1}$ Silesian University of Technology, Department of Heating, Ventilation and Dust Removal \\ Technology, Poland \\ ${ }^{2}$ International Centre for Indoor Environment and Energy, Department of Civil Engineering, \\ Technical University of Denmark
}

\begin{abstract}
Room airflow interaction, particularly in the breathing zone, is important to assess exposure to indoor air pollution. A breathing thermal manikin was used to simulate a room occupant with the convective boundary layer (CBL) generated around the body and the respiratory flow. Local airflow against the face of the manikin was applied to increase the complexity of the airflow interaction. $\mathrm{CO}_{2}$ was released at the armpits and $\mathrm{N}_{2} \mathrm{O}$ at the groin to simulate the respective bio-effluents generated at these two body sites. The tracer gas concentration at the mouth/nose of the manikin was measured with gas analyzers with short and long response times, respectively. The tracer gas concentration was characterized by the mean, standard deviation and 95th percentile values. The results revealed that the measurement time needed to determine, with sufficient accuracy, these parameters decreased substantially with a decrease in the response time of the gas analyzer. When only CBL was present, shorter measurement time was needed for the accurate concentration measurement of the tracer gas released close to the breathing zone. For more complex flow, as a result of CBL interaction with the exhalation flow, the needed measurement time was longer. It has been concluded that the accurate exposure assessment requires that the concentration measurements are performed only during the inhalation period. Therefore, gas analysers with low response time and sampling time that is considerably shorter than the inhalation period have to be used.
\end{abstract}

\section{Keywords}

Tracer gas concentration measurement, response time of gas analyzer, flow interaction, breathing, exposure 


\section{Introduction}

Indoor air quality affects occupants' health, comfort and performance. Building materials, office equipment, and occupants are some of the indoor pollution sources. Occupants pollute indoor air by continuous body released bio-effluents and by the exhaled air as well as by bioaerosol shedding from their skin, clothes and hair [1, 2]. Various human activities like cooking, smoking, vacuuming, cleaning, walking, etc. are also major contributors to the indoor air pollution burden [3-8]. The released pollution may cause SBS symptoms [9]. Therefore, the exposure assessment is important.

One of the paths of the occupants' exposure to the indoor pollution is respiration, i.e. inhalation of the polluted air. Airflows in rooms and around a human body transport pollution to the breathing zone and thus, modify the exposure. The convective boundary layer (CBL) around the human body in a calm environment, the transient flow of respiration and the flow generated by ventilation are some of the flows interacting in the breathing zone of the occupants. The convective boundary layer has been studied and described [10-17]. The importance of the CBL with respect to the transport of pollution to the breathing zone has been documented $[10,11,18]$. The contaminated exhaled air disturbs the CBL, can penetrate it, and spreads to other occupants [19]. Depending on the air distribution method the ventilation flow may be assisting, transverse, or opposing the CBL [20]. In general, the airflow interaction in a person's micro-environment is one of the most important factors influencing the exposure to the pollution released close to the body [10, 11, 19-24]. The interaction of flows around the human body is complex and transient in time [25, 26]. Understanding the characteristics of different airflow interactions in the breathing zone will contribute to the accurate assessment of the exposure to the indoor pollutants and to a better design of efficient air distribution systems providing the occupants with high quality of the inhaled air and thermal comfort. Therefore, the accurate measurement of the flow characteristics such as air speed, temperature, and the gaseous contaminants concentration is important.

The concentration of gaseous contaminants that people are exposed to indoors changes randomly in time. It can be described by time averaged concentration, standard deviation of the concentration fluctuations, and their $95^{\text {th }}$ percentile. Most often, the exposure and its impact on the occupants' health is assessed from the mean concentration measurements. 
However, it is still not clear whether the $95^{\text {th }}$ percentile of the concentration should be considered as more relevant for the exposure assessment.

In previous studies the physical experiments were typically performed in full-scale test rooms, and the human body was simulated by using breathing thermal manikins [27, 28]. A tracer gas was used to simulate the gaseous contaminants, e.g., a tracer gas mixed with the exhaled air was used to simulate respiratory pollution or it was released either from different sites on the manikin's body to simulate bio-effluents or in different locations in room to simulate particular pollution sources. Typically, to assess the transport and the exposure, the tracer gas concentration measurements were performed in the breathing zone of the manikin (close to the nose or the mouth). Two important factors have to be considered for the accurate exposure assessment, namely, the complex airflow interaction around the human body, particularly in the breathing zone, and the characteristics of the measuring instruments and the method of data analyses. The breathing thermal manikins with complex body shapes and the average person size allow for the mimicking of the CBL around the body and the human breathing cycle and mode with sufficient accuracy required for many studies. Different ventilation flows can also be organized in the full-scale rooms. This allows us to simulate with good approximation, the airflow interaction around the human body and to study its impact on the exposure. Furthermore, the measurement of the tracer gas concentration may be critical for the exposure assessment. Since the nature of the flow characteristics is stochastic, the dynamic characteristics of the measuring instruments are important. In general, the instruments used for the concentration measurements are slow and their response time and sampling period are considerably longer than the breathing cycle of a sedentary person (approx. $2.5 \mathrm{~s}$ inhalation, $2.5 \mathrm{~s}$ exhalation and $1 \mathrm{~s}$ pause). This may lead to an inaccurate exposure assessment because concentration measurements are performed during the entire breathing cycle instead of only during the inhalation period, i.e. the tracer gas concentration is measured also during the exhalation phase of the breathing cycle when an the airflow clean of tracer gas is generated. It has been shown that an open-path Fourier transform infrared (OPFTIR) spectrometer can be used to ensure faster spatial tracer gas distribution in an empty room when compared to multipoint-sample concentration measurements [29]. However, the data at a particular point cannot be obtained faster than one sample per 6 minutes, which is too slow, and the measurement principle requires that the optical path between the emitter of the infrared radiation and the detector should be ensured which is often impossible in practice. This method can be used to measure spatial concentration distributions of one or two gases 
emitted from sources with either constant emission or with a simple pattern of emission, such as a short impulse or constantly increased/decreased emission.

The aim of the paper is to identify the importance of the sampling frequency, of the response time of the tracer gas analyzer and of the tracer gas sampling only during the inhalation cycle for the tracer gas concentration measurements. Another goal is to assess the required measurement time and develop a data analysis method for the accurate exposure assessment.

\section{Methods}

\subsection{Experimental set-up}

Experiments were performed in a climate chamber with the dimensions $4.7 \mathrm{~m} \times 6 \mathrm{~m} \times 2.5 \mathrm{~m}$ $(\mathrm{W} \times \mathrm{L} \times \mathrm{H})$. The chamber was ventilated and air-conditioned by an upward piston flow. The air was supplied through a porous textile covering the entire floor area of the chamber on the top of which there was a steel coarse grid with square openings $(2 \times 2 \mathrm{~cm})$. The supply air in the chamber was $100 \%$ outdoor air, with no recirculation. The supply airflow rate was controlled by an electronic fan speed control software and the fan was kept to operate constantly throughout the experiment. The air was exhausted through a square opening (the area of which was $0.144 \mathrm{~m}^{2}$ ) in the ceiling above the manikin. The chamber construction ensured conditions with uniform temperature and negligible radiant temperature asymmetry. The air temperature in the room was kept $23^{\circ} \mathrm{C}$ during all the measurements.

During the measurements, a breathing thermal manikin was used to realistically simulate a sitting person. The manikin resembled an average Scandinavian woman, $1.7 \mathrm{~m}$ tall. The manikin had 23 body segments and each had an individual control to maintain surface temperature equal to the skin temperature of an average person in a state of thermal comfort. The average surface temperature of the manikin's individual segments ranged from 32.0 to $34.8^{\circ} \mathrm{C}$ during the experiments. The manikin was dressed in thin-tight outfit (a T-shirt, underwear, tight-fitting trousers, socks, and shoes). The thermal insulation of the clothing together with the chair was equal to 0.55 clo. The manikin had a short-haired wig. The thermal manikin's breathing process was simulated with an artificial lung located outside the chamber. The device was connected by two plastic tubes and connectors (situated on the lower back of the manikin) to the manikin's mouth and nose. The breathing frequency, pulmonary ventilation rate, and the temperature of the exhaled air were set to be the same as 
those of a person engaged in light sedentary activity. The manikin was set to inhale the air through its nose and exhale through its mouth, and vice versa. The pulmonary ventilation rate was $6 \mathrm{~L} / \mathrm{min}$. The breathing frequency was 10 times per minute with a cycle of $2.5 \mathrm{~s}$ of inhalation, $2.5 \mathrm{~s}$ of exhalation and $1 \mathrm{~s}$ of the pause [30]. The exhaled air was heated to $34^{\circ} \mathrm{C}$ but not humidified. The thermal manikin's nostrils were round openings, each with the crosssectional area of $38.5 \mathrm{~mm}^{2}$. The jets emerging from the nostrils were deflected $40^{\circ}$ downwards from the horizontal [31]. The mouth of the manikin was an ellipsoidal opening with the cross-sectional area of $158 \mathrm{~mm}^{2}$.

The manikin was located approximately in the middle of the chamber, seated on a computer chair in front of a desk with the arms resting on the table (Fig. 1). A wooden plate ( $2 \mathrm{~m} \times$ $1.21 \mathrm{~m}$ ) was placed below the manikin to prevent the supply airflow to disturb the $\mathrm{CBL}$ produced by the thermal manikin. The mean air speed was measured at several locations in the chamber and around the manikin when it was unheated. The air speed was measured with a multichannel low velocity thermal anemometer with spherical sensor (the accuracy of the readings was $\pm 0.02 \mathrm{~m} / \mathrm{s} \pm 2 \%$ ). It was lower than $0.05 \mathrm{~m} / \mathrm{s}$, i.e. a quiescent environment was present in the chamber [10]. The manikin was leaned $10^{\circ}$ backwards from the vertical axis. There was a $10 \mathrm{~cm}$ gap between the edge of the desk and the manikin's abdomen. The desk was equipped with personalized ventilation (PV) supplying clean air towards the face of the manikin from a round movable panel diffuser (RMP). The RMP had a circular outlet with diameter of $0.185 \mathrm{~m}$. A detailed description of the RMP can be found in [32]. Previous study showed that the personalised flow supplied by the RMP against the face could penetrate the CBL and provided clean air for breathing when its target velocity was higher than 0.3-0.35 $\mathrm{m} / \mathrm{s}$ [32]. The supply air temperature and the airflow rate of the PV system were controlled. The RMP was positioned $30 \mathrm{~cm}$ from the manikin's face which is one of the positions most preferred by the users [33]. The PV was used at two supplied air flow rates of $3 \mathrm{~L} / \mathrm{s}$ and $6 \mathrm{~L} / \mathrm{s}$, generating the mean velocity of $0.2 \mathrm{~m} / \mathrm{s}$ and $0.4 \mathrm{~m} / \mathrm{s}$, respectively, over the target area at the face of the manikin, $100 \mathrm{~mm}$ in diameter. The supply air temperature of the PV flow was kept constant at $23{ }^{\circ} \mathrm{C}$. A local exhaust, referred in the following as a ventilated cushion (VC), covered the seat and the backrest of the chair, i.e. the manikin was seated on the VC. The surface of the VC in contact with the manikin's body had numerous openings, $6 \mathrm{~mm}$ in diameter, which were used to exhaust air. Thus, the VC worked as a local exhaust aiming to capture and exhaust "contaminants" released from the manikin's body. The flow rate of the exhausted air was measured and controlled with the accuracy of $\pm 3 \%$ by adjusting the speed 
of the fan in the exhaust duct. The VC is described in [25]. This part of the set-up is shown in Fig. 2.

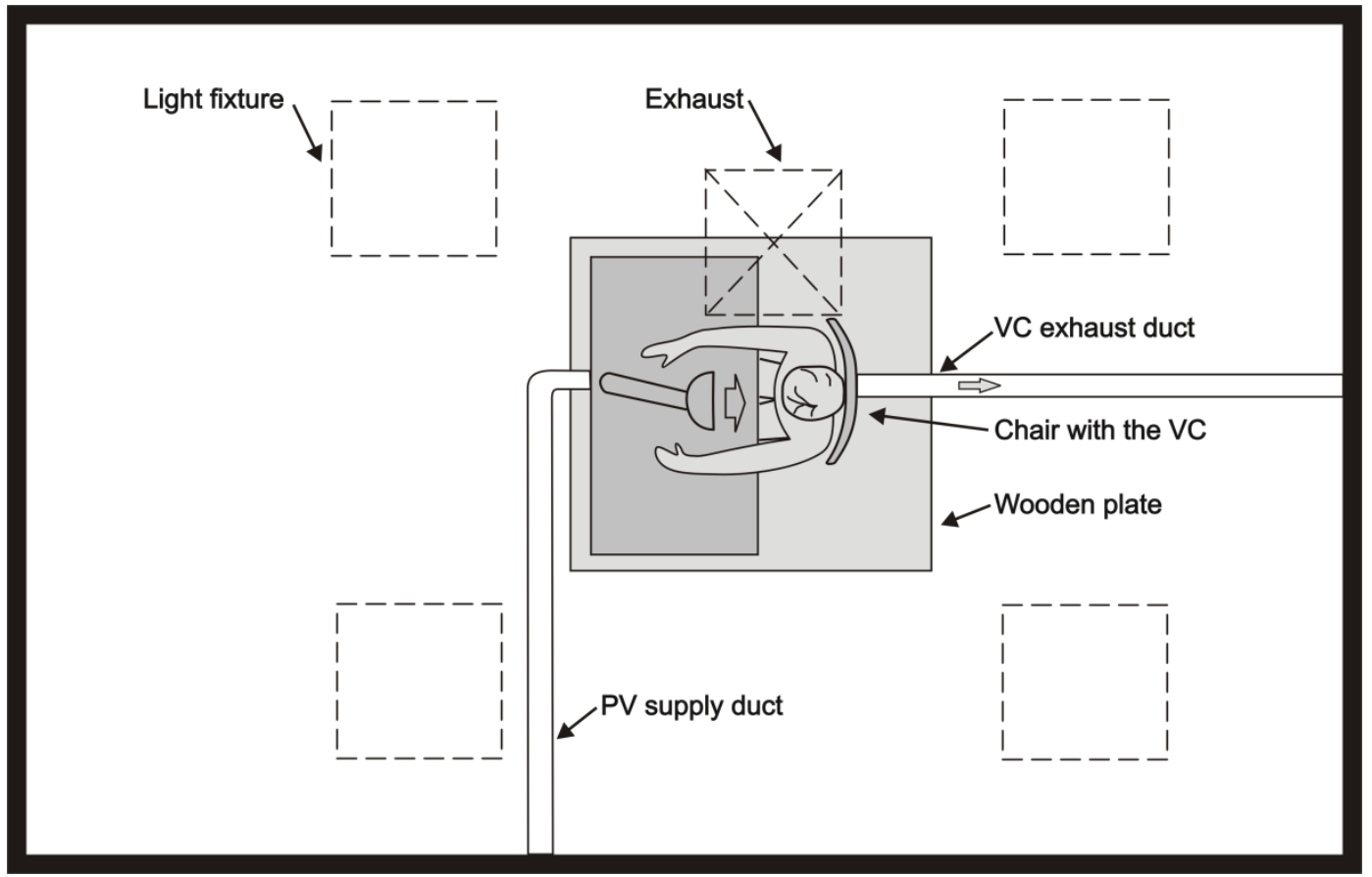

Fig. 1. Experimental set-up
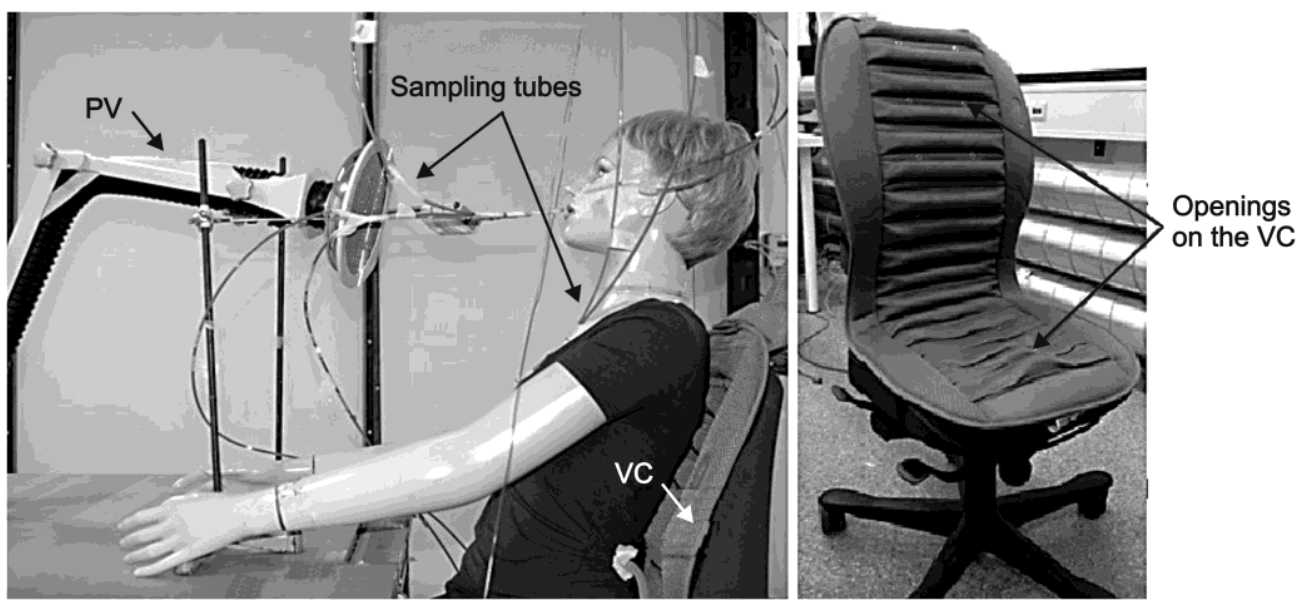

Fig. 2. a): Thermal manikin seated on the chair with the integrated ventilated cushion (VC) in front of the table equipped with the PV; b): chair with the ventilated cushion.

Dermally emitted bio-effluents were simulated by tracer gases. Carbon dioxide $\left(\mathrm{CO}_{2}\right)$ and nitrous oxide $\left(\mathrm{N}_{2} \mathrm{O}\right)$ were released from the manikin's armpits and groin area, respectively. The tracer gases were dosed at constant emission rates directly from the compressed gas cylinders. The gases were transported from the cylinders to the manikin through separate 
pipes and released through porous stones (height: $2.5 \mathrm{~cm}$; and diameter: $1.2 \mathrm{~cm}$ ) that were attached to the polluting body parts, ensuring that the gases were released, with the speed lower than $2 \mathrm{~cm} / \mathrm{s}$ (estimated based on the flow rate and the surface area of the porous stone). The emission rates of $\mathrm{CO}_{2}$ and $\mathrm{N}_{2} \mathrm{O}$ were adjusted to be $1.2 \mathrm{~L} / \mathrm{min}$ and $0.5 \mathrm{~L} / \mathrm{min}$, respectively.

$\mathrm{CO}_{2}$ and $\mathrm{N}_{2} \mathrm{O}$ were used in this study as they absorb infrared radiation well, which was the operating principle of the measuring instrument with fast response time described in the next section. These gases were not toxic in the concentration ranges used in the experiments. The properties of the used tracer gases differed from those of the air. The densities of the gases were higher than the air density and equal to $1.83 \mathrm{~kg} / \mathrm{m}^{3}$ for both $\mathrm{N}_{2} \mathrm{O}$ and $\mathrm{CO}_{2}$. The tracer gas was transported at the room temperature to the two body sites. However, when released its temperature increased due to the local heat generated by the body.

\subsection{Measuring instruments}

Two types of gas analysers were used to measure the concentrations of $\mathrm{CO}_{2}$ and $\mathrm{N}_{2} \mathrm{O}$ : a photoacoustic gas monitor (Innova) and a gas analyser with a nondispersive infrared detector (FCM41). The sampling rate of the Innova gas analyser, further called the "slow" instrument, was $0.025 \mathrm{~Hz}$. The fast gas concentration meter FCM41, called the "fast" instrument, had the time constant of $0.8 \mathrm{~s}$ and the sampling rate of $4 \mathrm{~Hz}$. Two Innova 1312 photoacoustic gas analyzers, with the expanded uncertainty (95\% confidence level) of $3 \%$ of the reading, were used in this study. Each Innova gas analyzer was connected to an Innova 1303 gas sampler. In order to obtain the fastest response from the Innova only one of the channels of the sampler was used when its measurements were compared with the measurements by FCM41. The expanded uncertainty of the FCM41 was $2 \%$ of the readings and \pm 20 ppm. Six "fast" instruments were used in this study: three for $\mathrm{N}_{2} \mathrm{O}$ and three for $\mathrm{CO}_{2}$ measurement. Detail description of the fast instrument is provided in $[34,35]$. The fast and the slow instruments were inter-calibrated before and after each experimental session. The slow instruments were also used to measure the $\mathrm{N}_{2} \mathrm{O}$ and $\mathrm{CO}_{2}$ concentrations in the air supplied to the chamber, the PV supply air and the exhaust air of the chamber.

\subsection{Airflow complexity in the breathing zone}


Numerous measurements with the fast and slow gas analyzers were performed for different complexities of the airflow interaction in the breathing zone. The experimental conditions included the presence of the CBL and a flow of exhalation through the mouth or nose, as well as more complex interaction of the CBL, the flow of exhalation and the local chair exhaust and/or PV in operation. The experimental conditions are described in detail together with the results in the following sections.

\subsection{Experimental procedure}

Continuous tracer gas measurements were performed simultaneously with the fast and the slow instruments. The $\mathrm{N}_{2} \mathrm{O}$ and $\mathrm{CO}_{2}$ concentrations were measured at the mouth (between the centers of the lips, at the distance of $0.5 \mathrm{~cm}$ ) and at the nose (at the opening of the left nostril). At each measurement location, separate $\mathrm{N}_{2} \mathrm{O}$ and $\mathrm{CO}_{2}$ fast meters sampled the gas through a plastic tube (diameter: $3 \mathrm{~mm}$; length: $1 \mathrm{~m}$ ). To avoid attaching many tubes to the manikin's face, the $\mathrm{N}_{2} \mathrm{O}$ and $\mathrm{CO}_{2}$ tubes at each sampling point were merged into one tube by using a Yshaped connector. Prior to each experiment, the breathing mode of the manikin, the supply flow rate of the PV, and the flow rate from the local exhaust were adjusted accordingly. The measurements with the FCM41 and the Innova instruments lasted 2 hours and 17 minutes.

\subsection{Data analyses}

Compensation of the data was performed for the time required for the $\mathrm{N}_{2} \mathrm{O}$ and $\mathrm{CO}_{2}$ samples to travel through the sampling tube from the measurement point to the fast gas analysers [34]. Fourier transformation was applied for the frequency correction of the signals from the instruments. The data collected with the fast instruments were analyzed in two different ways: analyses based on the samples collected during the continuous measurement with and without breathing comprising the complete breathing cycle and analyses based on the samples measured only during the inhalation period of the breathing cycle. The results obtained with the slow instrument were based on the samples of the continuous measurements with and without the complete breathing cycle (note that the sampling period of the instrument was considerably longer than the breathing cycle). The mean, standard deviation and $95^{\text {th }}$ percentile were calculated based on more than 32768 and 205 samples of the tracer gas obtained from the fast and the slow instruments, respectively, during 1365 breathing cycles. The $95^{\text {th }}$ percentile is the value at which 95 percent of the measured samples have a lower values and only $5 \%$ have higher values. It should be noted that the $\mathrm{CO}_{2}$ background level of 
$480 \mathrm{ppm}$ in the chamber was subtracted from the total $\mathrm{CO}_{2}$ concentration at each measurement point.

Based on the data collected by the fast instrument, the power spectral density and the cumulative spectrum of the standard deviation were obtained. The power spectral density describes how the power of the signal is distributed over the frequency range (Eq. A.5 in Appendix A). The cumulative spectrum is the curve wherein, for a given frequency, each point is calculated as the area under the particular energy spectrum from the lowest frequency to this frequency (Eq. A.8 in Appendix A).

\section{Results}

The samples of the instantaneous values of the $\mathrm{N}_{2} \mathrm{O}$ concentration at the mouth of the manikin measured with fast and slow gas analyzers are presented when the breathing function of the manikin was ON (Fig. 3a) and OFF (Fig. 3b) .

a)

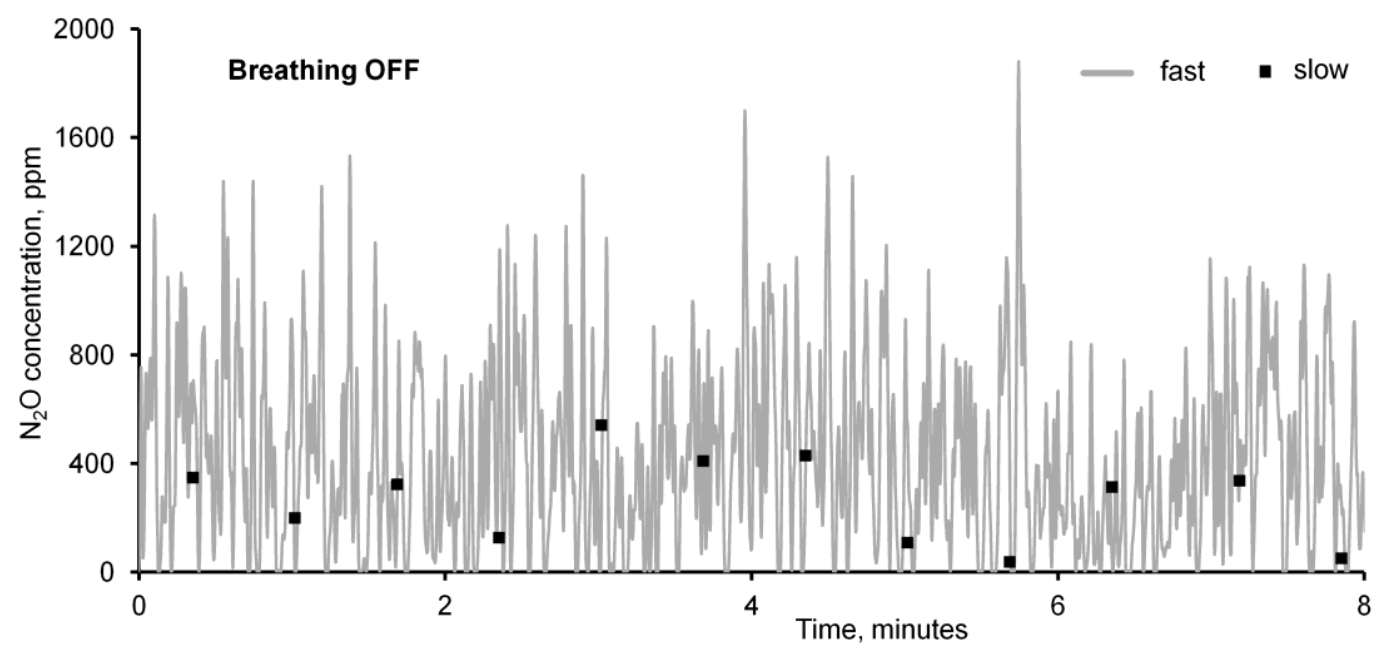


b)

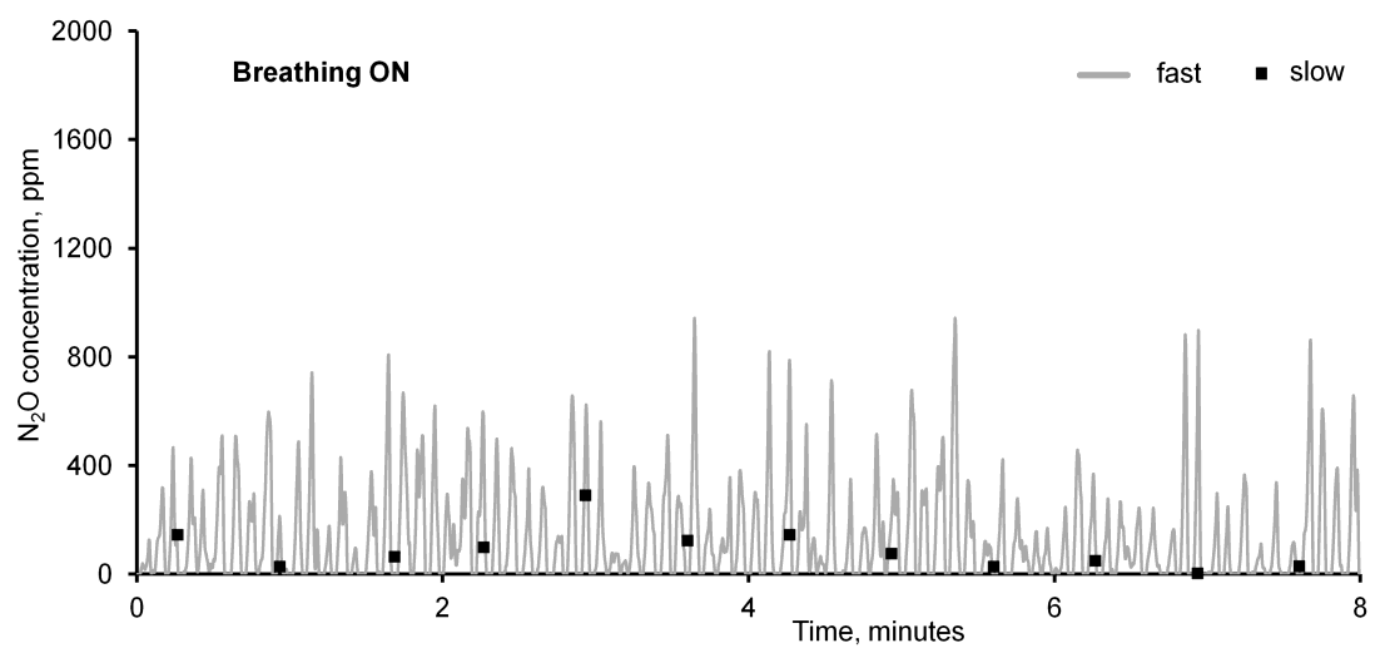

Fig. 3. Samples of the instantaneous values of the $\mathrm{N}_{2} \mathrm{O}$ concentration recorded continuously at the mouth (exhalation nose/inhalation mouth) with the fast and slow gas analyzers when the breathing function was OFF (a) and ON (b). PV and VC were not in operation.

The results in the figures show that the gas analyzer with the slow response and the long time period of sampling cannot capture the concentration fluctuations. The results show that the fluctuations are less random when the breathing function is $\mathrm{ON}$ and they are determined by the breathing cycle (10 cycles per minute). In each breathing cycle, during exhalation, the tracer gas concentration measured at the mouth decreases almost to zero.

\section{Importance of the measurement time}

The effect of the measurement time on the accuracy of the determination of the mean concentration, standard deviation and $95^{\text {th }}$ percentile was studied. For the entire measurement period ( $2 \mathrm{~h}$ and $17 \mathrm{~min}$ ), the three parameters were obtained and assumed to be "the true values". The same three parameters were then calculated for shorter time periods, the subsets of the entire measurement period. In this way different measurement time was simulated. This measurement time changed from 1 to 120 minutes. Upon changing the initial time of the simulated measurement, fluctuations of the mean value, standard deviation, and $95^{\text {th }}$ percentile were found and they were characterized by standard deviations. These standard deviations were considered as the absolute standard uncertainty of the mean value, of the standard deviation, and of the $95^{\text {th }}$ percentile because of the limited measurement time. The "true values" were used to obtain the relative uncertainties (Eq. B.10-12 in Appendix B), as shown in Fig. 4, Fig. 5 and Fig.6. The results in the figures reveal that the uncertainty is lower when the measurements are performed with the fast analyzers. The measurement time 
required to obtain the mean concentration values with 5\% uncertainty was approx. 15 min and was almost three times shorter than the time required for the "slow" analyzer. The differences for the standard deviation and the $95^{\text {th }}$ percentile were considerably higher, e.g., the $95^{\text {th }}$ percentile of the concentration was obtained with $5 \%$ uncertainty based on 15 min records of the continuous measurement by the "fast" instrument and 90 min records of the measurements by the "slow" instrument.
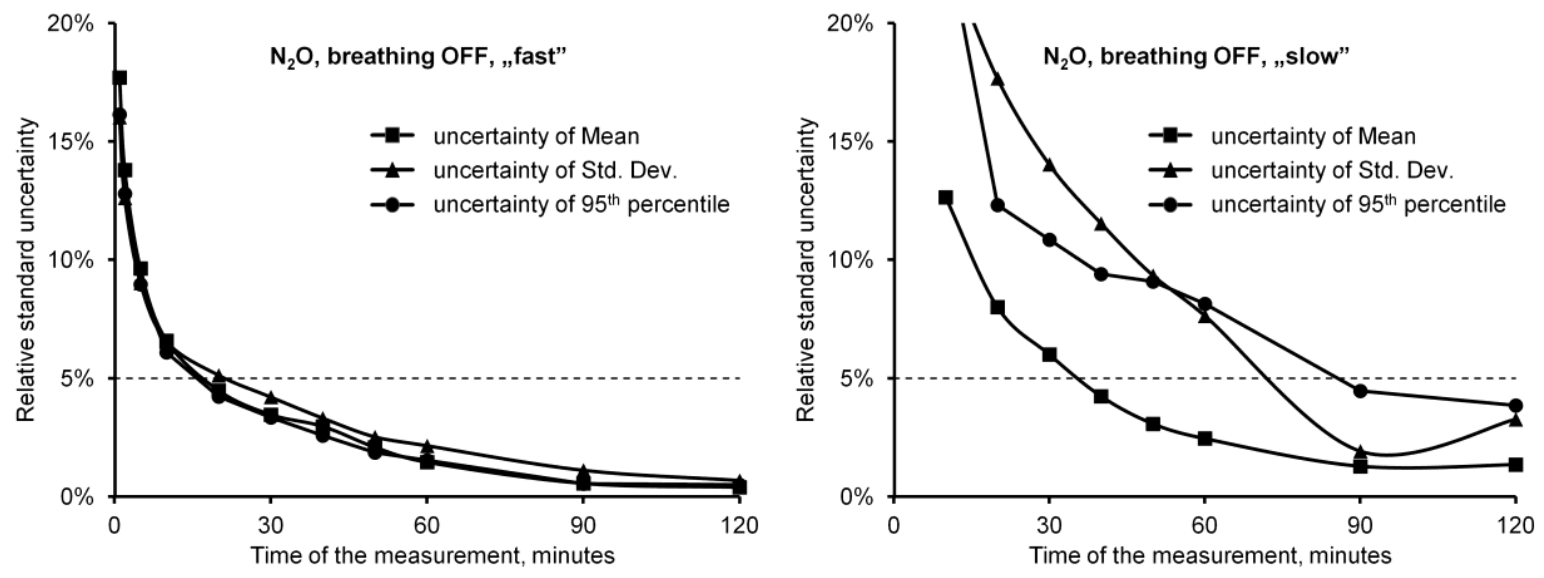

Fig. 4. Relative standard uncertainty of the mean concentration, standard deviation, and $95^{\text {th }}$ percentile of the concentration measured with the fast (a) and slow (b) gas analyzers. Results shown for $\mathrm{N}_{2} \mathrm{O}$ released at the groin in the case of breathing OFF, i.e., the presence of CBL only. PV and VC were not in operation.
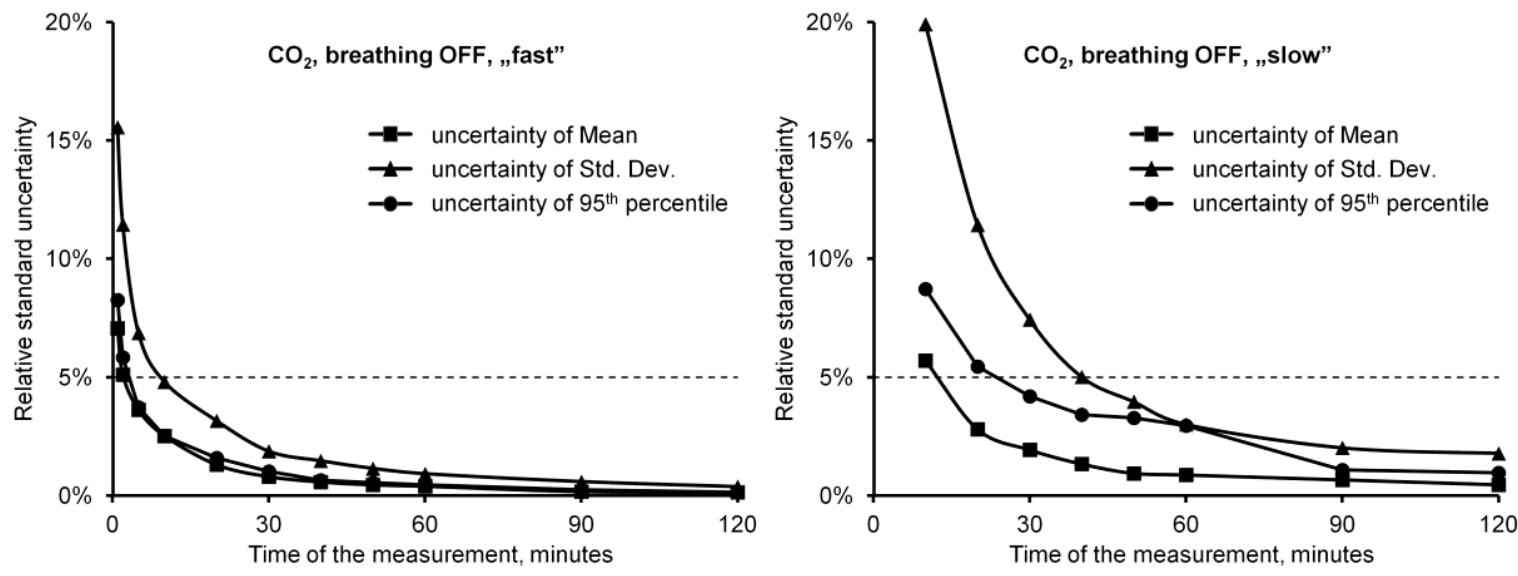

Fig. 5. Relative standard uncertainty of the mean concentration, standard deviation and $95^{\text {th }}$ percentile of the concentration measured with the fast (a) and slow (b) gas analyzers. Results shown for the $\mathrm{CO}_{2}$ released at the armpits in the case of breathing OFF, i.e., the presence of CBL only. PV and VC were not in operation. 


\section{Importance of the location of the tracer gas release}

The results shown in Fig. 4 and Fig. 5 indicate that the location of the tracer gas release is also important. $\mathrm{N}_{2} \mathrm{O}$ was released at the groin, i.e. relatively far from the mouth/nose while $\mathrm{CO}_{2}$ was released at the armpits, i.e. closer to the measurement point. The uncertainty became lower when the tracer gas was released near the measurement point. To obtain the mean, standard deviation, and $95^{\text {th }}$ percentile with the same accuracy, shorter measurements were required for $\mathrm{CO}_{2}$ than $\mathrm{N}_{2} \mathrm{O}$, e.g. to obtain the mean concentration of $\mathrm{N}_{2} \mathrm{O}$ with $5 \%$ accuracy the measurement time of 15 min was required for the "fast" instrument and of 40 min for the "slow" instrument, while for $\mathrm{CO}_{2}$ this time was 5 and $20 \mathrm{~min}$, respectively.

\section{Importance of airflow interaction in the breathing zone}

Breathing generates transient flow that interacts with the CBL. The interaction depends on several factors, including breathing mode (exhalation from mouth or nose), posture of the head, strength of the CBL, etc. The resultant flow is more complex than the CBL, which in real life typically does not exist alone. The flow interaction affects the inhaled air quality, i.e. the exposure. From this perspective, it is important to know how the complexity of the flow in the breathing zone affects the accuracy of the tracer gas measurements.

Figure 6 shows the uncertainty in the determination of the mean, standard deviation, and $95^{\text {th }}$ percentile of the $\mathrm{N}_{2} \mathrm{O}$ and $\mathrm{CO}_{2}$ concentration in the case of interaction of CBL with the exhalation flow when the VC was operating. The measurements were performed with the "fast" analyzer. The results in the figure show the differences compared to the case of breathing OFF, i.e. the presence of CBL only (Fig. 4a and Fig. 5a). First, the more complex flow as a result of breathing increased the time required to perform the measurements with the same uncertainty as in the case of breathing OFF, particularly when the tracer gas was released closer to the measurement point. For example, in the case with breathing ON (Fig. 6b) 20 min measurements were required to obtain the $95^{\text {th }}$ percentile of the $\mathrm{CO}_{2}$ concentration with the uncertainty of $5 \%$, while only 5 min measurements were required when breathing was OFF (Fig. 5a). Second, the impact of the location of the tracer gas release was different. When breathing was $\mathrm{ON}$, to achieve the same level of uncertainty the time required for the concentration measurement was longer for $\mathrm{CO}_{2}$ than for $\mathrm{N}_{2} \mathrm{O}$ (Fig. 6). This was opposite when the breathing was OFF (Fig. 4a and Fig. 5a). However, more tests are needed to find whether the observed dependences are systematic. 
Generally, it can be concluded that the required measurement time depends on the flow interaction of CBL, the breathing flow and the operation of the ventilated cushion as well as on the location of the contamination source. In the case of the "fast" instruments it changes from 5 to 20 minutes and for the "slow" instrument from 40 to 90 minutes. A conservative assumption can be made to perform the measurements with the "fast" instruments for 30 minutes and with the "slow" instruments for 120 minutes.
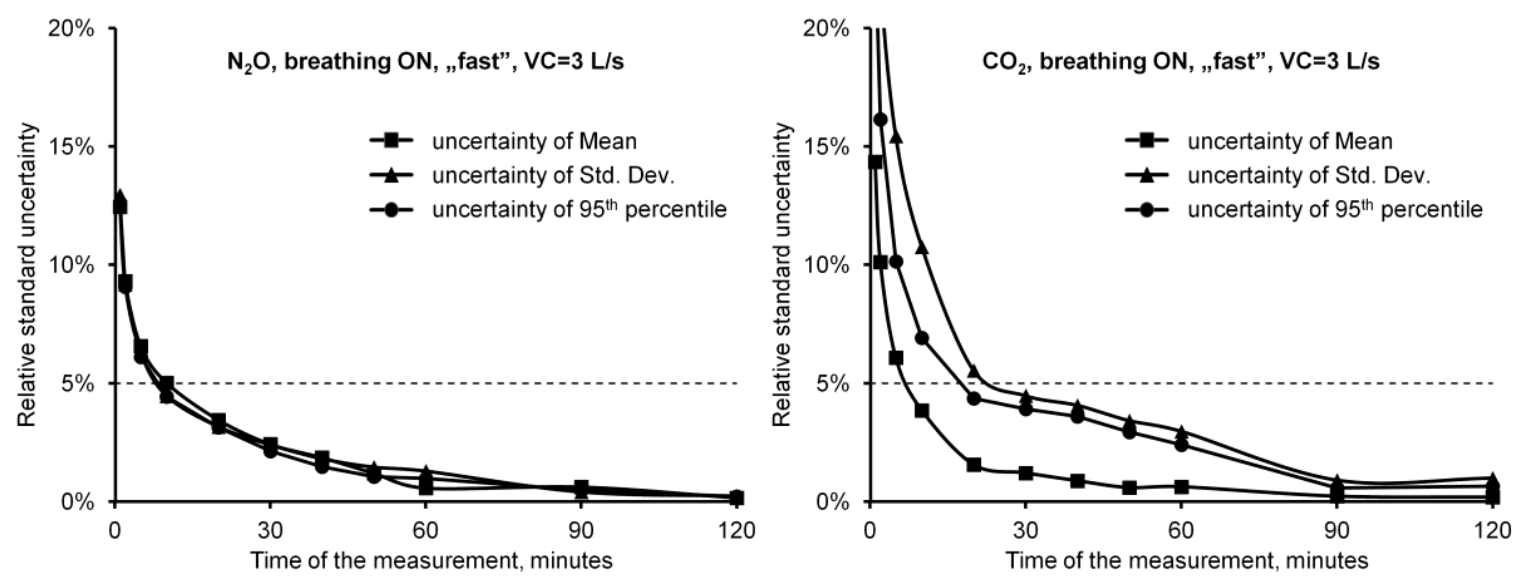

Fig. 6. Relative standard uncertainty of the mean, standard deviation, and $95^{\text {th }}$ percentile of the concentration measured with the fast gas analyzers when the breathing is ON. The results for $\mathrm{N}_{2} \mathrm{O}$ released at the groin (a) and $\mathrm{CO}_{2}$ released at the armpits (b) are shown in the case of the ventilated cushion (VC) operating at $3 \mathrm{~L} / \mathrm{s}$. PV was not in operation.

\section{Importance of the data analyses}

The breathing process is transient and typically includes inhalation, exhalation and pause. With respect to the exposure due to respiration, only the inhalation period is important. Thus, when a tracer gas is used to simulate gaseous pollutants its concentration has to be measured either in the inhaled air or close to the mouth or nose but only during the inhalation period. Therefore, gas analyzers with fast response time have to be used. The importance of this issue was studied, and the results are presented in the following.

Numerous tracer gas concentration measurements were performed with the fast analyzer under different breathing modes (inhalation mouth/exhalation nose/pause and inhalation nose/exhalation mouth/pause) and different complexities of the flow interaction in the breathing zone (with and without PV, with and without VC, etc.), Table 1. Fig. 7 and Fig. 8 show records from the measurements with breathing only and breathing combined with PV. In Fig. $7 \mathrm{~b}$ and Fig. $8 \mathrm{~b}$ the $\mathrm{CO}_{2}$ concentration excess is presented, as the difference between the measured $\mathrm{CO}_{2}$ concentration and $\mathrm{CO}_{2}$ concentration in the supplied air. In order to be able to 
extract the concentrations measured only during the inhalation periods, the inhalation and exhalation signals were synchronized in time. This led to the possibility of identifying the exhalation periods in the measured signals as periodically repeating fragments with very low concentration (approx. $0 \mathrm{ppm}$ ). Consequently, a binary signal of the entire breathing process was obtained, using which it was possible to extract the inhalation cycles.

Table 1 List of the performed measurement cases for different experimental setup.

\begin{tabular}{|c|c|c|c|c|}
\hline \multirow{2}{*}{$\begin{array}{c}\text { Personal } \\
\text { ventilation } \\
\text { PV }\end{array}$} & \multicolumn{4}{|c|}{ Ventilated cushion (VC) } \\
\cline { 2 - 5 } & $0 \mathrm{~L} / \mathrm{s},($ VC OFF) & $1.5 \mathrm{~L} / \mathrm{s}$ & $3 \mathrm{~L} / \mathrm{s}$ & $5 \mathrm{~L} / \mathrm{s}$ \\
\hline \multirow{2}{*}{$\begin{array}{c}0 \mathrm{~m} / \mathrm{s},(\mathrm{PV} \\
\mathrm{OFF})\end{array}$} & No breathing & No breathing & Inh. nose/Exh. mouth & Inh. nose/Exh. mouth \\
\cline { 2 - 5 } & Inh. mouth/Exh. nose & Inh. mouth/Exh. nose & & \\
\hline & Inh. nose/Exh. mouth & Inh. nose/Exh. mouth & & No breathing \\
\hline \multirow{2}{*}{$0.2 \mathrm{~m} / \mathrm{s}$} & No breathing & No breathing & & Inh. nose/Exh. mouth \\
\cline { 2 - 5 } & Inh. nose/Exh. mouth & Inh. nose/Exh. mouth & & \\
\hline \multirow{2}{*}{$0.4 \mathrm{~m} / \mathrm{s}$} & No breathing & & & \\
\cline { 2 - 5 } & Inh. nose/Exh. mouth & & & \\
\hline
\end{tabular}

Note that in Fig. 7b, Fig. 8a and Fig. 8b concentration peaks may be observed which were measured at the nose during the exhalation periods of the breathing cycle. These peaks are due to the airflow interaction in the breathing zone, which increased the tracer gas concentration at the nose even when the manikin was exhaling air. These results confirm that the airflow interaction between the CBL and the flow of exhalation, and also during the conditions when clean air is supplied toward the face is complex. Therefore, if the concentration signals are not treated properly the exposure to the pollutants can be under- or over-estimated.

a)

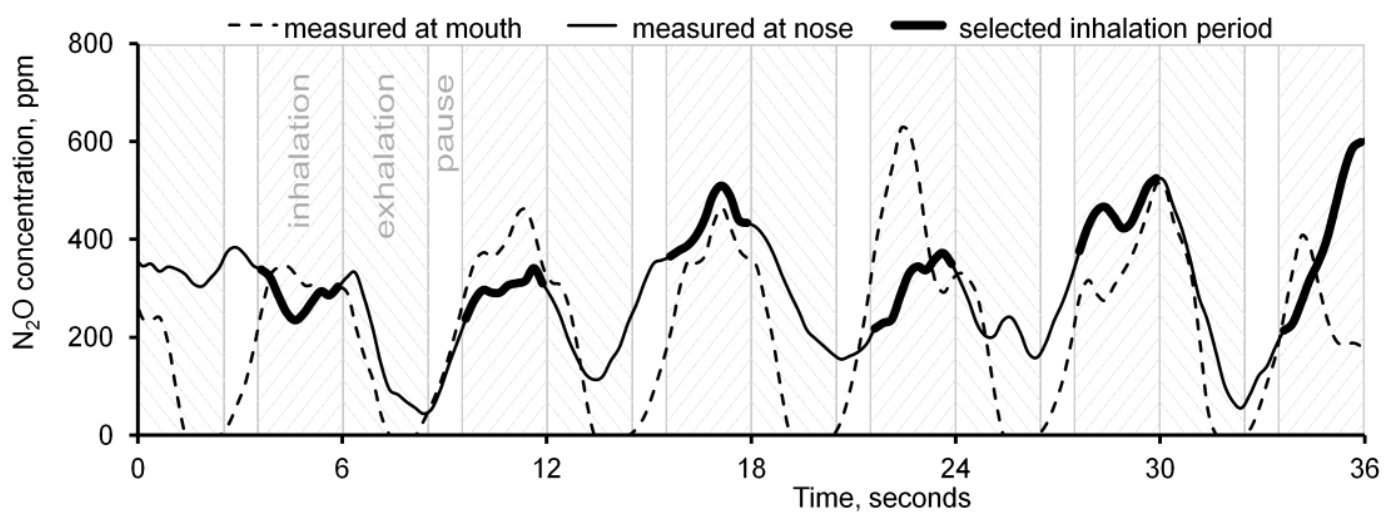

b) 


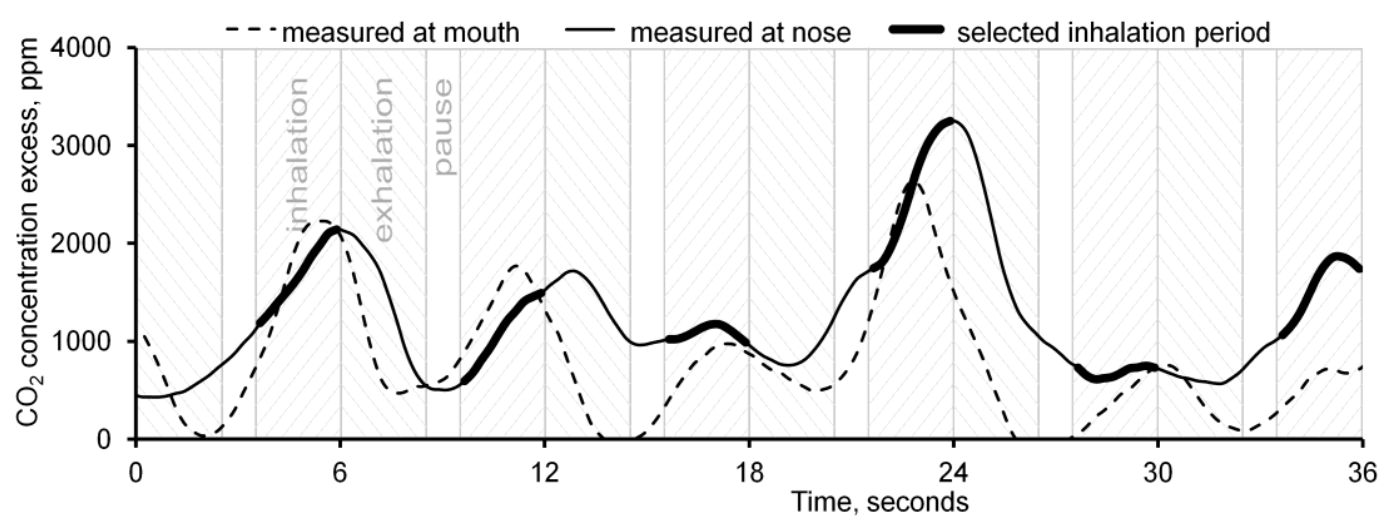

Fig. 7. Records of $\mathrm{N}_{2} \mathrm{O}$ (a) and $\mathrm{CO}_{2}$ (b) concentration for six breathing periods. Measurements performed with the fast analyzer in case of breathing only (inhalation nose / exhalation mouth / pause). PV and VC were not in operation.

a)

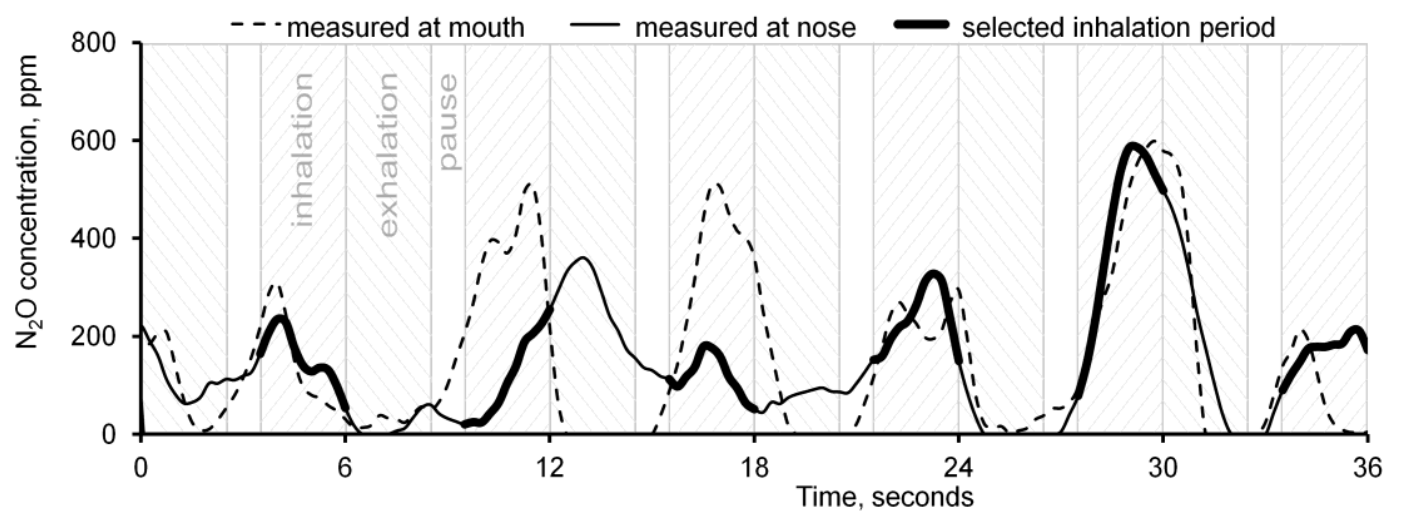

b)

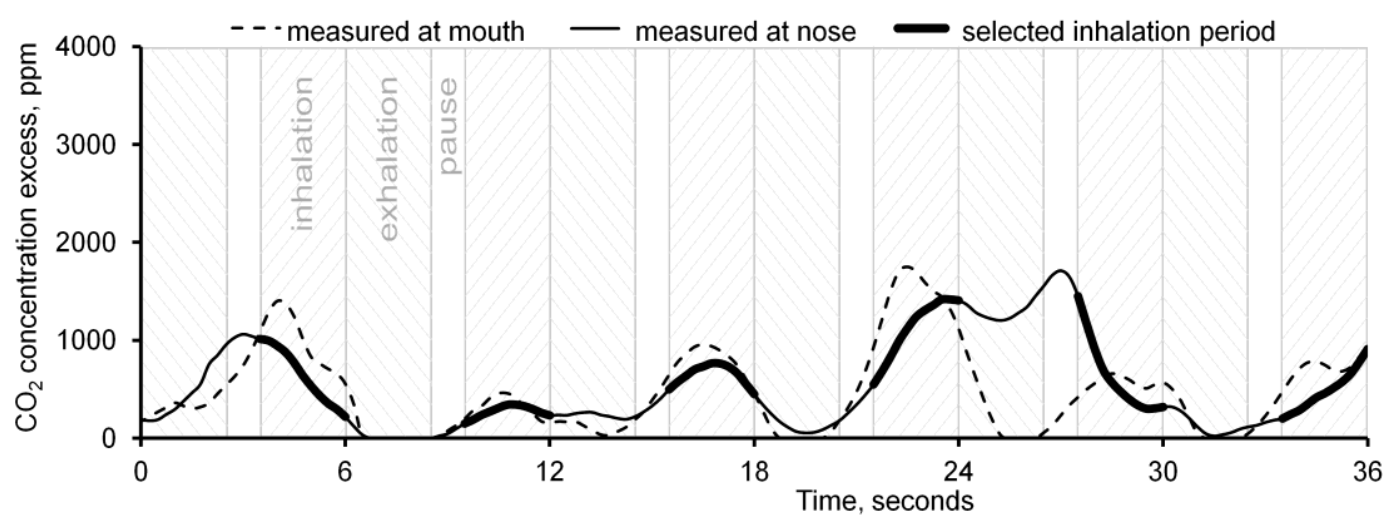

Fig. 8. Records of $\mathrm{N}_{2} \mathrm{O}$ (a) and $\mathrm{CO}_{2}$ (b) concentration for six breathing periods. Measurements are performed with the fast analyzer in case of breathing combined with PV. The breathing mode inhalation nose / exhalation mouth / pause is shown. VC was not in operation.

The concentration has a periodic component, which results from the interaction of the "contaminated" air flow in the convective boundary layer near the manikin body with the air movement caused by breathing. For the case presented in Fig. 7a with exhalation through the 
mouth and inhalation through the nose it can be seen that during the exhalation phase, the exhaled clean air decreases the concentration of $\mathrm{N}_{2} \mathrm{O}$ sampled at the mouth to zero, which can be expected. However, the jet of the exhaled air entrains the surrounding air, and the $\mathrm{N}_{2} \mathrm{O}$ concentration during the exhalation phase decreases also near the nose. There is a difference between the mean values of the $\mathrm{N}_{2} \mathrm{O}$ concentration at the nose averaged for the entire measurement time and averaged only for the inhalation phase. For the six cycles of breathing presented in Fig. 7a, the mean value of the $\mathrm{N}_{2} \mathrm{O}$ concentration averaged for the entire measurement time is equal to $297 \mathrm{ppm}$, whereas the $\mathrm{N}_{2} \mathrm{O}$ concentration averaged only for the inhalation phase is by $22 \%$ higher and is equal to $362 \mathrm{ppm}$. At the end of the exhalation phase, the $\mathrm{N}_{2} \mathrm{O}$ concentration starts to increase and during the 1 second pause (between the exhalation and the inhalation phases) the $\mathrm{N}_{2} \mathrm{O}$ concentration is rebuilt.

The results in the figures show that the phases of breathing (inhalation, exhalation, and pause) are not sharply defined by the measured tracer gas concentration. Nevertheless, it was possible to define the ranges of the sampled concentration, corresponding to the breathing phases, with acceptable approximation.

The analyzed results were used to calculate the mean, standard deviation, and $95^{\text {th }}$ percentile of the measured tracer gas concentration. Some of the obtained results are shown in Fig. 9a. The mean concentration (272 ppm) and the STD (106 ppm) based on the measurements taken only during the inhalation phases were respectively by $56 \%$ higher and by $25 \%$ lower than the mean concentration $(174 \mathrm{ppm})$ and the STD (142 ppm) estimated for the entire breathing period (Fig. 9a). The $95^{\text {th }}$ percentile values differed little. The results presented in Fig. 9a also show that the concentration characteristics obtained only for the inhalation period were almost the same as in the case without breathing. These results are in accordance with those of Melikov and Kaczmarczyk [31] who showed that the concentrations of the polluted room air measured in the air inhaled by a breathing thermal manikin in a calm environment were almost the same as those measured close to the upper lip of a non-breathing thermal manikin. However, it can be seen in Fig. 9a that the estimated mean and the $95^{\text {th }}$ percentile based on the concentration measured during the entire breathing period are lower than in the other two cases.

In Fig. $9 \mathrm{~b}$ the results of the $\mathrm{N}_{2} \mathrm{O}$ concentration measurements under more complex flow interaction, including CBL, inhalation nose/exhalation mouth/pause, and the PV airflow 
toward the face, are shown. A comparison of the results obtained from the concentration measured only in the inhaled air and those obtained in the case of no breathing simulation shows considerable differences. In contrast, no difference is observed in the $\mathrm{N}_{2} \mathrm{O}$ concentration measured only during the inhalation period and the $\mathrm{N}_{2} \mathrm{O}$ measured for the entire breathing period. Thus, depending on the airflow interaction in the breathing zone, the exposure can be considerably different.

When the pollution was generated at the armpits, the mean, standard deviation, and 95th percentile of the $\mathrm{CO}_{2}$ concentration obtained for only the inhalation periods were slightly higher than those estimated for the entire breathing period or the "no breathing" case (Fig. 10a and Fig. 10b). The reason for the small difference may be the interaction of the exhalation jet from the mouth with the manikin's convective boundary layer, which causes mixing in the breathing zone of the pollution generated at the armpits. The mixing effect is not diminished during the $1 \mathrm{~s}$ pause, thereby resulting in the $\mathrm{CO}_{2}$ concentration peaks at the nose even during the exhalation period from the mouth. This effect is shown in Fig. 7b and Fig. 8b. Bivolarova et al. [25] also described this effect and reported that the exhalation from the nose and inhalation from the mouth increased the exposure to the armpit-emitted pollutants compared to the case "Inhalation nose/exhalation mouth/ pause".
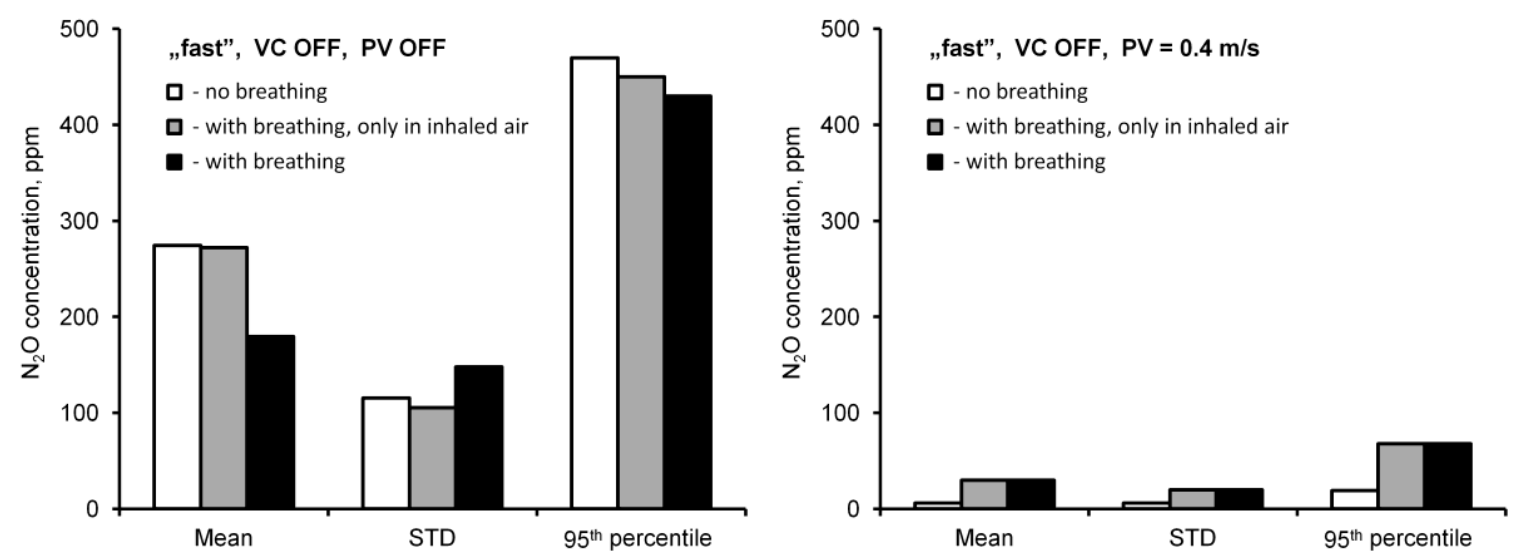

Fig. 9. The mean, standard deviation, and $95^{\text {th }}$ percentile of the $\mathrm{N}_{2} \mathrm{O}$ concentration measured with the fast gas analyzer. The results based on the measurements in the case without breathing are compared during the entire breathing cycle (inhalation/exhalation/pause) and only during the inhalation period for the case where VC and PV were not in operation (a), and for the case where PV was in operation (b). 

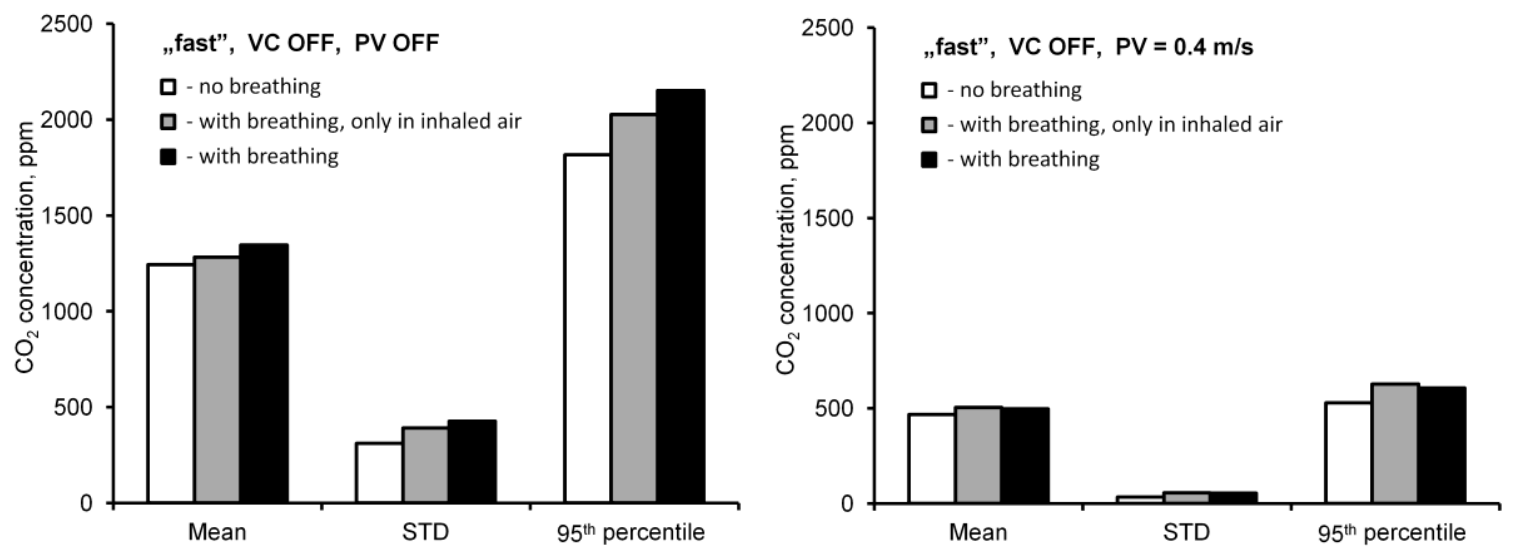

Fig. 10. The mean, standard deviation, and $95^{\text {th }}$ percentile of the $\mathrm{CO}_{2}$ concentration measured with the fast gas analyzer. The results based on the measurements in the case without breathing are compared during the entire breathing cycle (inhalation/exhalation/pause) and only during the inhalation period for the case where VC and PV were not in operation (a), and for the case where PV was in operation (b).

\section{Discussion}

The assessment of the exposure to the indoor air pollution with tracer gas method and breathing thermal manikin can be incorrect when the mean concentration is estimated based on the concentration measurements during the entire breathing cycle. The results of this study reveal that the mean concentration during the entire breathing cycle of the tracer gas simulating bio-effluents emitted from the groin, for the case with CBL and breathing only, is by $36 \%$ lower than the mean tracer gas concentration measured only during the inhalation period. This leads to an incorrect exposure assessment. The main reason is the low tracer gas concentration in the exhaled air. This problem can be solved by the use of tracer gas analyzers with fast response time and short sampling rate that are able to collect enough samples only during the inhalation period (typically $2.5 \mathrm{~s}$ ). Gas analyzers with long response time can measure the concentration accurately if the inhaled tracer gas is collected, e.g. in bags, and then analyzed. However, in this case the important information regarding the $95^{\text {th }}$ percentile of the concentration fluctuation cannot be obtained.

The results of this study confirm that correct tracer gas concentration can be measured at the upper lip of a thermal manikin without breathing when ventilation flow is not applied to the breathing zone [31]. However, when additional ventilation flow is introduced at the breathing zone proper simulation of breathing and measurement only during the inhalation period is needed for accurate concentration measurement. 
The results of the present study reveal that the $95^{\text {th }}$ percentile of the tracer gas concentration can be twice as much as the mean concentration. Tracer gas measurements are often used to predict the risk of airborne cross-infection. The question is "which of these two quantities is more important for an exposure assessment in general and for the prediction of the risk of airborne cross-infection in particular"? Although the answer to this question can be different depending on the conditions (e.g. room airflow, location of air pollution source, exhalation mouth or exhalation nose, type, generation rate and infectivity of the virus, etc.), it can be recommended that fast instruments should be used for the concentration measurement especially in the case when complete mixing of the pollution is not present in the air in the breathing zone. The present results also show that this will substantially reduce the measurement time required to obtain the mean, standard deviation and $95^{\text {th }}$ percentile with sufficient accuracy.

The airflow interaction in the breathing zone is important for the reduction of the exposure to harmful indoor pollutants. Owing to the techniques available thus far (laser Doppler anemometer, Particle Image Velocimetry System, etc.) the airflow interaction in the breathing zone has been studied with a focus on the velocity field $[12,36]$. The gas analyzer developed and used in the present study makes it possible to study the dynamics of the gas concentration distribution in the breathing zone. Fig. 11 presents the power spectral density and the cumulative spectra of the standard deviation of the $\mathrm{N}_{2} \mathrm{O}$ concentration fluctuations measured at the mouth of the thermal manikin. The results obtained with breathing OFF and breathing ON (inhalation nose/exhalation mouth/pause) are compared. 

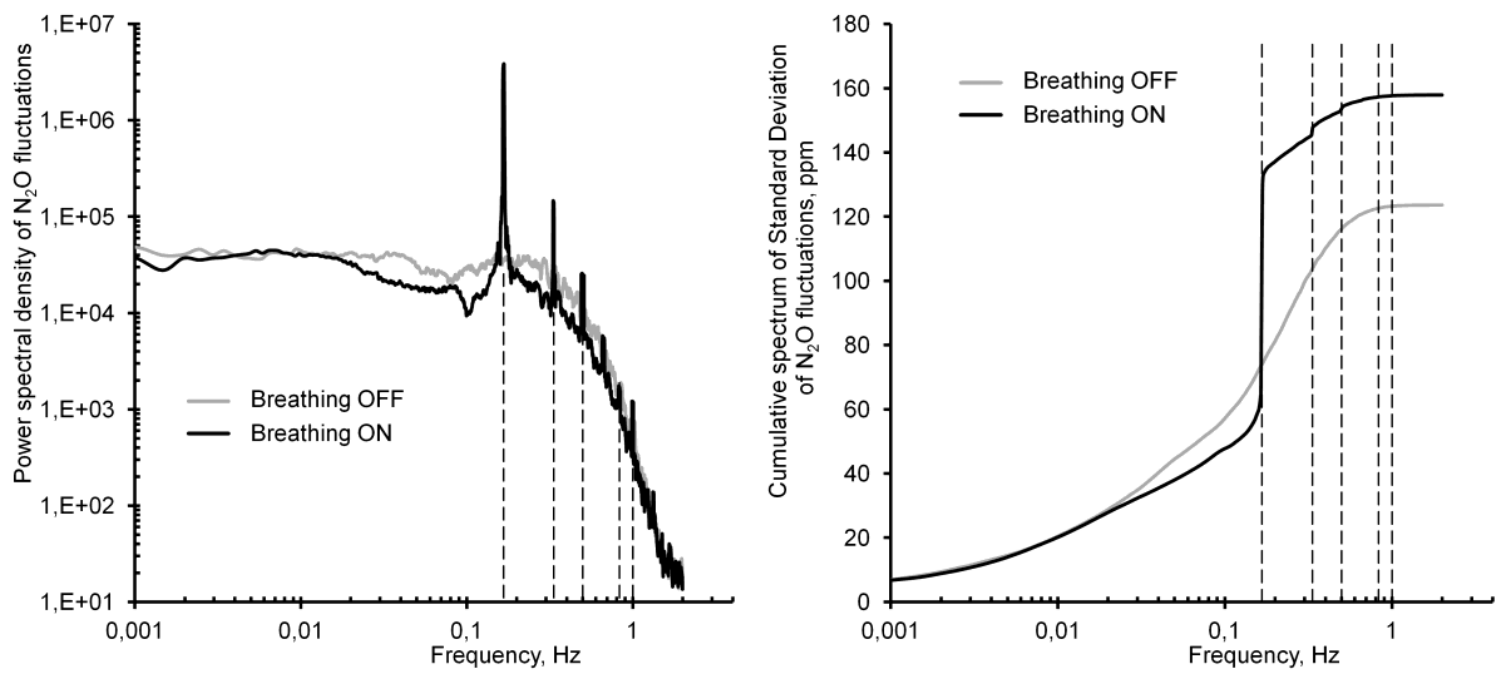

Fig. 11. Power spectral densities (a) and STD cumulative spectrum (b) of $\mathrm{N}_{2} \mathrm{O}$ concentration fluctuations. Measurements at the mouth of the thermal manikin.

The results in the figures show that in the case with breathing ON, peaks in the power spectral density of up to the $6^{\text {th }}$ harmonic of the breathing frequency $(1 / 6 \mathrm{~Hz})$ can be seen. The periodical exhalation of the clean air decreases to zero $\mathrm{N}_{2} \mathrm{O}$ concentration at the mouth of the thermal manikin for approx. 5/12 of the cycle time. In the case with breathing ON, the standard deviation of the $\mathrm{N}_{2} \mathrm{O}$ concentration is by $33 \%$ higher than in the case without breathing and the contribution of the periodic and random components to the standard deviation is approx. 50\%:50\%. The need for a realistic simulation of the airflow interaction is clear.

In the present study, continuous records of the tracer gas concentration were analyzed to define the inhalation part of the signal. In the future, this process can be improved and software can be used to make the selection based on signals from the artificial lung. Future investigation should also consider placing a tube in the mouth or nose of the manikin to sample the air and using a three-way valve controlled by artificial lung to sample the air by gas analyser the air only during the inhalation period.

\section{Study limitation}

The measurements were performed in the room with upward piston flow. Such air distribution ensures a quiescent environment in the manikin surroundings with low air velocity, constant background concentration of the tracer gases and very low thermal stratification. In the case of mixing or displacement air distribution systems, constant tracer gas concentration is not 
maintained in the manikin surroundings. Fluctuations in the gas concentration may make the identification of the flow interaction in the breathing zone more difficult. In displacement ventilation, due to high thermal stratification, so-called lock-up phenomenon is observed [37]. At a certain height the exhaled air moves with the oscillating trajectory and can be entrained by CBL. Thus, the identification of the flow interaction in the manikin microenvironment seems more difficult in the room with mixing and displacement air distribution systems. This needs to be studied.

In the present study the exposure to gaseous, bio-effluent contaminants, released from the sources located at the groin and the armpits, was tested. Contamination from sources placed out of the human microenvironment may interact with the breathing flow and CBL in a different way. The present results refer only to gaseous contaminants, not to particulate pollutants, and this is another limitation of the study.

\section{Conclusions}

The performed tests have shown that the assessment of the exposure to the indoor air pollution with the tracer gas method and the breathing thermal manikin can be incorrect when the tracer gas concentration is estimated based on the concentration measurements during the entire breathing cycle. To assess the exposure, the measurements of the mean and the $95^{\text {th }}$ percentile of concentration at the mouth/nose should be performed only during the inhalation period by a gas analyzer with short response time $(0.8 \mathrm{~s}$ or shorter).

For complex flow interaction (CBL, exhaled flow and additional flow against the face) the tracer gas concentration measured at the upper lip without breathing will not be the same as the concentration measured only during the inhalation period of the breathing cycle. Therefore, the proper simulation of breathing and the measurement only during the inhalation period are recommended.

\section{Acknowledgements}

This work was supported by the European Union $7^{\text {th }}$ framework program HEXACOMM FP7/2007-2013 under grant agreement No 315760 and statutory work No. 08/010/BK_17/0024 funded by the Polish Ministry of Science and Higher Education 


\section{References}

1. Nazaroff WW. Indoor bioaerosol dynamics. Indoor Air. 2016 Feb;26(1):61-78.

2. Licina D, Tian YL, Nazaroff WW. Inhalation intake fraction of particulate matter from localized indoor emissions. Building and Environment. 2017 Oct;123:14-22.

3. Singer BC, Pass RZ, Delp WW, Lorenzetti DM, Maddalena RL. Pollutant concentrations and emission rates from natural gas cooking burners without and with range hood exhaust in nine California homes. Building and Environment. 2017 Sep;122:215-29.

4. Chan WR, Sidheswaran M, Sullivan DP, Cohn S, Fisk WJ. Cooking-related PM2.5 and acrolein measured in grocery stores and comparison with other retail types. Indoor Air. 2016 Jun;26(3):489-500.

5. Acevedo-Bolton V, Ott WR, Cheng KC, Jiang RT, Klepeis NE, Hildemann LM. Controlled experiments measuring personal exposure to PM2.5 in close proximity to cigarette smoking. Indoor Air. 2014 Apr;24(2):199212.

6. van Strien RT, Driessen M, Oldenweining M, Doekes G, Brunekreef B. Do central vacuum cleaners produce less indoor airborne dust or airborne cat allergen, during and after vacuuming, compared with regular vacuum cleaners? Indoor Air. 2004 Jun;14(3):174-7.

7. Shin HM, McKone TE, Bennett DH. Model framework for integrating multiple exposure pathways to chemicals in household cleaning products. Indoor Air. $2017 \mathrm{Jul} ; 27(4): 829-39$.

8. Tian Y, Sul K, Qian J, Mondal S, Ferro AR. A comparative study of walking-induced dust resuspension using a consistent test mechanism. Indoor Air. 2014 Dec;24(6):592-603.

9. Tsushima S, Bekö G, Bossi R, Tanabe S, Wargocki P. Measurements of Dermal and Oral Emissions from Humans. 14th international conference of Indoor Air Quality and Climate; 2016; Ghent, Belgium; 2016.

10. Licina D, Melikov A, Sekhar C, Tham KW. Transport of gaseous pollutants by convective boundary layer around a human body. Science and Technology for the Built Environment. 2015 Nov;21(8):1175-86.

11. Rim D, Novoselac A, Morrison G. The influence of chemical interactions at the human surface on breathing zone levels of reactants and products. Indoor Air. 2009 Aug;19(4):324-34.

12. Licina D, Pantelic J, Melikov A, Sekhar C, Tham KW. Experimental investigation of the human convective boundary layer in a quiescent indoor environment. Building and Environment. 2014 May;75:79-91.

13. Lewis HE, Foster AR, Mullan BJ, Cox RN, Clark RP. Aerodynamics of the human microenvironment. The Lancet.293(7609):1273-7.

14. Voelker C, Maempel S, Kornadt O. Measuring the human body's microclimate using a thermal manikin. Indoor Air. 2014 Dec;24(6):567-79.

15. Homma H, Yakiyama M. Examination of free convection around occupant's body caused by its metabolic heat. ASHRAE Transactions; 1988; Dallas, USA; 1988. p. 104-24.

16. Zukowska D, Melikov A, Popiolek Z. Impact of personal factors and furniture arrangement on the thermal plume above a sitting occupant. Building and Environment. 2012 Mar;49:104-16.

17. Gao NP, Niu JL. CFD study of the thermal environment around a human body: A review. Indoor and Built Environment. $2005 \mathrm{Feb} ; 14(1): 5-16$.

18. Rim D, Novoselac A. Transport of particulate and gaseous pollutants in the vicinity of a human body. Building and Environment. 2009 Sep;44(9):1840-9.

19. Cermak R, Melikov AK. Protection of occupants from exhaled infectious agents and floor material emissions in rooms with personalized and underfloor ventilation. Hvac\&R Research. 2007 Jan;13(1):23-38.

20. Melikov AK, Cermak R, Kovar O, Forejt L. Impact of airflow interaction on inhaled air quality and transport of contaminants in rooms with personalized and total volume ventilation. 7th International Conference on Healthy Buildings 2003; 2003; Singapore; 2003. p. 592-7.

21. Bivolarova MP, Rezgals L, Melikov AK, Bolashikov ZD. Exposure Reduction to Human Bio-effluents Using Seat-integrated Localized Ventilation in Quiescent Indoor Environment. Proceedings of the 12th Rehva World Congress; 2016; Aalborg Denmark; 2016.

22. Bolashikov ZD, Nikolaev L, Melikov AK, Kaczmarczyk J, Fanger PO. Personalized ventilation: air terminal devices with high efficiency. 7th International Conference on Healthy Buildings 2003; 2003; Singapore; 2003. 
23. Cermak R, Melikov AK, Forejt L, Kovar O. Performance of personalized ventilation in conjunction with mixing and displacement ventilation. Hvac\&R Research. 2006 Apr;12(2):295-311.

24. Melikov AK. Human body micro-environment: The benefits of controlling airflow interaction. Building and Environment. 2015 Sep;91:70-7.

25. Bivolarova M, Kierat W, Zavrl E, Popiolek Z, Melikov A. Effect of airflow interaction in the breathing zone on exposure to bio-effluents. Building and Environment. 2017 Nov;125:216-26.

26. Villafruela JM, Olmedo I, Jose JFS. Influence of human breathing modes on airborne cross infection risk. Building and Environment. 2016 Sep;106:340-51.

27. Bogdan A, Koelblen B, Chludzinska M. Influence of a breathing process on the perception of the thermal environment using personalised ventilation. Building and Environment. 2016 Feb;96:80-90.

28. Jiang N, Yao SY, Feng LY, Sun HJ, Liu JJ. Experimental study on flow behavior of breathing activity produced by a thermal manikin. Building and Environment. 2017 Oct;123:200-10.

29. Drescher AC, Park DY, Yost MG, Gadgil AJ, Levine SP, Nazaroff WW. Stationary and time-dependent indoor tracer-gas concentration profiles measured by OP-FTIR remote sensing and SBFM-computed tomography. Atmospheric Environment. 1997 Mar;31(5):727-40.

30. Hyldgaard CE. Humans as a source of heat and air pollution. 4th International Conference on air distribution in rooms, Roomvent 1994; 1994; Cracow, Poland; 1994. p. 413-33.

31. Melikov A, Kaczmarczyk J. Measurement and prediction of indoor air quality using a breathing thermal manikin. Indoor Air. 2007 Feb;17(1):50-9.

32. Bolashikov Z, Nikolaev L, Melikov AK, Kaczmarczyk J, Fanger PO. New air terminal devices with high efficiency for personalized ventilation application. NUS Press Pte Ltd; 2003. p. 850-5.

33. Kaczmarczyk J, Zeng Q, Melikov AK, Fanger PO. Individual control and people's preferences in an experiment with a personalized ventilation system. Proceedings of Roomvent 2002; 2002. p. 57-60.

34. Kierat W, Popiolek Z. Dynamic properties of fast gas concentration meter with nondispersive infrared detector. Measurement. 2017 Jan;95:149-55.

35. Kierat W, Popiolek Z. Methods of the gas concentration sinusoidal and step changes generation for dynamic properties of gas concentration meters testing. Measurement. 2016 Jun;88:131-6.

36. Licina D, Melikov A, Sekhar C, Tham KW. Human convective boundary layer and its interaction with room ventilation flow. Indoor Air. 2015 Feb;25(1):21-35.

37. Bjorn E, Nielsen PV. Dispersal of exhaled air and personal exposure in displacement ventilated rooms. Indoor Air. 2002 Sep;12(3):147-64. 


\section{Appendix A}

\section{Parameters characterizing the concentration changes in the time and frequency domains}

The instantaneous concentration $C(\tau)$ can be decomposed into mean value $\bar{C}$ and fluctuations $C^{\prime}(\tau)$ :

$$
C(\tau)=\bar{C}+C^{\prime}(\tau)
$$

The mean value $\bar{C}$ of the concentration is defined according to the following equation:

$$
\bar{C}=\lim _{\tau_{R} \rightarrow \infty} \frac{1}{\tau_{R}} \int_{0}^{\tau_{R}} C(\tau) d \tau
$$

The variance of the concentration fluctuations $\overline{C^{\prime 2}}$ is defined as follows:

$$
\overline{C^{\prime 2}}=\lim _{\tau_{R} \rightarrow \infty} \frac{1}{\tau_{R}} \int_{0}^{\tau_{R}}[C(\tau)-\bar{C}]^{2} d \tau
$$

The standard deviation (RMS) $C^{*}$ of the fluctuations is calculated from the variance value as follows:

$$
C^{*}=\sqrt{\overline{C^{\prime 2}}}
$$

The power spectral density $\Phi_{C}(f)$ of the concentration fluctuations is calculated as the averaged squared value of fluctuations filtered in a band-pass filter of frequency $f$ and a bandwidth $\Delta f$ :

$$
\Phi_{C}(f)=\lim _{\tau_{R} \rightarrow \infty} \lim _{\Delta f \rightarrow 0} \frac{1}{\tau_{R} \cdot \Delta f} \int_{0}^{\tau_{R}} C^{\prime 2}(f, \Delta f, \tau) d \tau
$$

The relationship of variance $\overline{C^{\prime 2}}$ and power spectral density $\Phi_{C}(f)$ is as follows:

$$
\overline{C^{\prime 2}}=\int_{0}^{\infty} \Phi_{C}(f) d f
$$

The cumulated power spectral density $\Psi_{C}(f)$ of the concentration fluctuations is the integral of the power spectral density $\Phi_{C}(f)$ and can be expressed as follows:

$$
\Psi_{C}(f)=\int_{0}^{f} \Phi_{C}(f) d f
$$

Cumulated standard deviation spectral density $\Psi_{C^{*}}(f)$ of concentration fluctuations is: 


$$
\Psi_{C^{*}}(f)=\left[\int_{0}^{f} \Phi_{C}(f) d f\right]^{1 / 2}
$$

\section{Appendix B}

Relative uncertainty of the mean concentration, standard deviation and $95^{\text {th }}$ percentile due to limited measurement time.

Based on instantaneous concentration $C(\tau)$ the mean concentration $\bar{C}$, standard deviation $C^{*}$ and $95^{\text {th }}$ percentile $C^{95}$ can be determined. The obtained values of those parameters depend on the starting moment of time $\tau_{s}$, and the measurement time $\tau_{m}$.

For selected measurement time $\tau_{m}$ the statistical parameters $\bar{C}, C^{*}$ and $C^{95}$ can be calculated by changing starting moment of time $\tau_{s}$. The estimators of mean concentration, standard deviation and $95^{\text {th }}$ percentile can be calculated from equations B.1, B.2 and B.3:

$$
\begin{aligned}
& \bar{C}_{\tau_{m}}\left(\tau_{s}\right)=\left.\bar{C}\right|_{\tau_{s}} ^{\tau_{s}+\tau_{m}} \\
& C_{\tau_{m}}^{*}\left(\tau_{s}\right)=\left.C^{*}\right|_{\tau_{s}} ^{\tau_{s}+\tau_{m}} \\
& C_{\tau_{m}}^{95}\left(\tau_{s}\right)=\left.C^{95}\right|_{\tau_{s}} ^{\tau_{s}+\tau_{m}}
\end{aligned}
$$

For given measurement time $\tau_{m}$, the changes of the estimators as a function of the starting moment of time $\tau_{S}$ can be characterized by a their standard deviation (Eq. B.4, Eq. B.5 and Eq. B.6). The starting moment of time $\tau_{s}$ may change from 0 to $\left(\tau_{\max }-\tau_{m}\right)$, where $\tau_{\max }$ is the longest measurement time during the experiment.

$$
\begin{aligned}
& {\left[\left.\bar{C}_{\tau_{m}}\left(\tau_{s}\right)\right|_{0} ^{\tau_{\max }-\tau_{m}}\right]^{*}} \\
& {\left[\left.C_{\tau_{m}}^{*}\left(\tau_{s}\right)\right|_{0} ^{\tau_{\max }-\tau_{m}}\right]^{*}}
\end{aligned}
$$




$$
\left[\left.C_{\tau_{m}}^{95}\left(\tau_{s}\right)\right|_{0} ^{\tau_{\max }-\tau_{m}}\right]^{*}
$$

These standard deviations were considered as the absolute standard uncertainty of the mean value, of the standard deviation, and of the $95^{\text {th }}$ percentile for the given measurement time $\tau_{m}$.

For the measurement time $\tau_{m}$ equal $\tau_{\max }$, the three parameters, $\bar{C}, C^{*}$ and $C^{95}$, were calculated and assumed to be "the true values" $\bar{C}_{\text {true }}, C_{\text {true }}^{*}$ and $C_{\text {true }}^{95}$. These "true values" were used to obtain the relative uncertainties for the given measurement time $\tau_{m}$, according to the following equations:

$$
\begin{aligned}
& u_{\bar{C}}\left(\tau_{m}\right)=\frac{\left[\bar{C}_{\tau_{m}}\left(\tau_{s}\right)\right]^{*}}{\bar{C}_{\text {true }}} \\
& u_{C^{*}}\left(\tau_{m}\right)=\frac{\left[C_{\tau_{m}}^{*}\left(\tau_{s}\right)\right]^{*}}{C_{\text {true }}^{*}} \\
& u_{C^{95}}\left(\tau_{m}\right)=\frac{\left[C_{\tau_{m}}^{95}\left(\tau_{s}\right)\right]^{*}}{C_{\text {true }}^{95}}
\end{aligned}
$$

